\title{
Are Corporate Carbon Management Practices Reducing Corporate Carbon Emissions?
}

\author{
Baran Doda, ${ }^{1}$ Caterina Gennaioli, ${ }^{1}$ Andy Gouldson, ${ }^{2 *}$ David Grover ${ }^{1}$ and Rory Sullivan ${ }^{3}$ \\ ${ }^{1}$ ESRC Centre for Climate Change Economics and Policy, LSE, London, United Kingdom \\ ${ }^{2}$ ESRC Centre for Climate Change Economics and Policy, University of Bristol, United Kingdom \\ ${ }^{3}$ ESRC Centre for Climate Change Economics and Policy, University of Leeds, United Kingdom
}

\begin{abstract}
This paper is the first large scale, quantitative study of the impact of corporate carbon management practices on corporate greenhouse gas (GHG) emissions. Using data for 2009 and 2010 from the Carbon Disclosure Project survey, we find little compelling evidence that commonly adopted management practices are reducing emissions. This finding is unexpected and we propose three possible explanations for it. First, it may be because corporate carbon data and management practice information have not been reported in a standardized way. Second, there may be a delay between the application of corporate carbon management practices and their impact on emissions performance. Third, carbon management practices are not sufficiently impact-oriented, meaning there is no relationship to observe. Our findings are important for policymakers designing corporate GHG reporting standards, for the multiple stakeholders trying to understand the drivers of corporate carbon performance, and for the corporate managers responsible for measuring, reporting and mitigating emissions. Copyright (c) 2015 The Authors. Corporate Social Responsibility and Environmental Management published by ERP Environment and John Wiley \& Sons Ltd.
\end{abstract}

Received 25 June 2014; revised 29 July 2014; accepted 31 July 2014

Keywords: corporations; greenhouse gas emissions; carbon management

\section{Introduction}

ORPORATIONS MAKE A SUBSTANTIAL CONTRIBUTION TO GLOBAL GREENHOUSE GAS (GHG) EMISSIONS. IN 2O1O, IT WAS estimated that the direct emissions of the world's 500 largest publicly listed corporations (the Global 500) accounted for II\% of total anthropogenic GHG emissions (CDP, 20I0). Given the scale of corporate emissions, governments, investors, non-governmental organization (NGOs), and consumers frequently call for corporations to adopt GHG reduction policies, to monitor and measure their emissions, to assign responsibility for emissions to managers, and to report these actions and outcomes to stakeholders (Hoffman, 2006; Gouldson \& Sullivan, 2007; Lee, 2012; Weinhofer \& Busch, 2013).

Many large corporations have responded to these pressures and adopted carbon management practices (CMPs) in recent years. For example, the proportion of the Global 500 with GHG emissions reduction targets increased 
from $43 \%$ in 2004 to $50 \%$ in 2010 , and to $82 \%$ in 2012 . The proportion of corporations that had allocated responsibility for climate-change-related issues to their board and/or senior management increased from $56 \%$ in 2006 to $85 \%$ in 2010, and to $96 \%$ in 2012 (CDP 2006; 2010; 2012).

Within the broader sphere of corporate energy and environmental management, there is a rapidly emerging literature that focuses specifically on carbon management practices (Hoffman, 2006; Pinkse \& Kolk, 2009; Lee, 20I2; Boiral et al., 20I2; Weinhofer \& Busch, 2013). This literature, which makes ample use of case studies, tends to find that the adoption of specific management practices can lead to corporation-level changes in energy use or GHG emissions (Bloom et al., 20I0; Bloom \& van Reenan, 20I0). However there have been few quantitative tests of the broad hypotheses proposed by this literature, with some exceptions (Theyel, 2000; Bloom et al., 20Io; Matsumura et al., 20II).

Other research has questioned whether environmental management practices actually influence corporate environmental performance (Dahlström et al., 2003; Ramus \& Montiel, 2005; Wu \& Teng, 20I4). Some see the adoption of carbon management practices as a form of 'greenwash' designed to legitimize existing corporate practice rather than change it (Greer \& Bruno, I996). Others even suggest these practices can be counterproductive to long-run improvements in corporate environmental performance by delaying the deep, transformative changes that appear to be ultimately needed to address pollution and resource over-use at their root (Konnola \& Unruh, 2007).

To our knowledge there is no large-scale empirical study of the impact of CMPs on GHG emissions across large corporations. One reason is the difficulty of generating and obtaining structured quantitative data on corporate CMPs themselves, given that there are few mandatory requirements on corporations to measure or report on their GHG emissions or management practices in a way that is consistent across corporations and countries.

In recent years, however, many of the world's largest corporations have voluntarily disclosed this information to the Carbon Disclosure Project (CDP). Over 80\% of the world's largest 500 corporations now voluntarily provide information to the CDP (CDP, 20I2). Their responses include information on senior management responsibilities for climate change, climate change risk management strategies, climate change policies, actions directed at reducing GHG emissions, capital investments and payback periods, objectives and targets, and GHG emissions calculation methodologies and assumptions.

To our knowledge, these are the most comprehensive and authoritative data available linking the presence of CMPs and the extent of their implementation, to carbon emissions at the level of the corporation. We use these data to explore a simple question in the remainder of this paper: is there an observable relationship between the application of CMPs in the world's largest corporations and the GHG emissions these practices are intended to reduce?

\section{Research Approach, Data and Methodology}

We address this question by constructing a new dataset that is organized at the level of the corporation-year, by developing a simple model to explain the change in GHG emissions intensity within each corporation from 2009 to 2010 , and by fitting the data to the model by simple ordinary least squares regression. We are interested in whether the explanatory variables of interest associate negatively with changes in emissions per unit of turnover.

We constructed the dataset from three separate sources. The first is the CDP survey of large corporations, which tells us the level of GHG emissions. ${ }^{\text {I }}$ The second is publically reported financial information about each corporation such as turnover, assets, and employee numbers. These data we obtained from the Orbis database through Bureau Van Dijk. The third is the information about CMPs that are applied in each corporation. These data were assembled by a company called ENDS Carbon, which used proprietary techniques (explained below) to extract information about the CMPs from the raw responses of corporations to the CDP survey.

The emissions data that form the basis for our dependent variable capture scope I and 2 emissions rather than emissions associated with the entire life cycle of the product the corporation sells. ${ }^{2}$ We focus on this variable because we expect corporations to have greater control over scope I and 2 emissions. We constructed the dependent

\footnotetext{
${ }^{\mathrm{I}}$ For the $20 \mathrm{I2}$ version of the CDP questionnaire, see https://www.cdproject.net/CDP\%20Questionaire\%20Documents/Investor-CDP-20I2Information-Request.pdf

${ }^{2}$ Scope I emissions are direct emissions from sources that are owned or controlled by the corporation, and scope 2 emissions are indirect GHG emissions from consumption of purchased electricity, heat or steam.
} 
variable as the change in emissions intensity (i.e., emissions per $\$$ of operating revenue) because variations in accounting and reporting conventions in voluntarily reported emissions data can create difficulties in comparing the level of emissions across corporations. However, looking at changes over time within individual corporations controls for this variation and gives grounds for more accurate measurement (Sullivan \& Gouldson, 20I2).

Our independent variables of interest are 23 distinct CMPs that may have been implemented by these corporations by 20I0. Table I describes these CMPs in detail. The complete dataset we received from ENDS Carbon contained I627 corporation-year observations of emissions, and CMP scores for 582 unique corporations. ${ }^{3}$ These were the most up-to-date data available to us from the most recently publically available survey results.

Using the CMPs as independent variables to explain the change in emissions intensity is a novel contribution of our study. To construct the CMP data, ENDS Carbon's analysts assigned a CMP-specific score to each corporation based on the corporation's responses to certain questions in the CDP questionnaire. For example, the corporation's response to the question, 'Are carbon emissions verified by a third party?' fed into ENDS Carbon's assessment of the depth of assurance for the corporation's emissions (i.e., Dor in Table I). A corporation's response to the question, 'Has the company made an explicit corporate policy commitment to limit or reduce carbon emissions?' fed into the assessment of the presence and extent of corporate policy commitments to deal with emissions (Por in Table I).

ENDS Carbon performed the scoring according to a framework that it developed in line with the ISO I4064 standard for quantifying, monitoring, reporting and verifying GHG emissions. ISO $\mathrm{I}_{4064}$ is, in turn, based on the GHG Protocol, an international GHG accounting framework developed by the World Resources Institute and the World Business Council for Sustainable Development.

ENDS Carbon grouped the 23 CMPs into four broader management practice categories: 'Policy and Targets (P\#)', 'Measurement (M\#)', 'Management and Decision-making (DM\#)' and 'Disclosures' (D\#), where \# varies within each category to indicate a specific CMP. Table 2 gives an example of the scoring criteria applied to one CMP and Table Ar in the appendix gives criteria for scoring maximum points for each CMP. 4

In our analysis we interpret a zero CMP score as the absence of that practice from the corporation's overall carbon management strategy during the year the scores were assigned. It is important to highlight that the scores refer to the state of the corporation's management practices in 20I0, the only year for which we have CMP data. We interpret a non-zero score as the presence of the practice. When the practice is present in a corporation, we interpret a higher score to mean that the technique has been implemented to a 'greater extent'.

The differences in the scales, which ENDS Carbon used when scoring individual CMPs, are arbitrary for the purposes of this paper. For example, in the raw data 'Mo4: GHG accounting methods' is scored on a scale from o to 4 whereas 'Por: Policy and commitments' uses a o Io scale. For convenience we re-scaled the scoring ranges in the raw data provided to us by ENDS Carbon to a common range of $\circ$ to 5 . This is reflected in descriptive statistics given in Table 3. This merely makes the scoring ranges of the CMPs comparable. It should be kept in mind that only the sign and statistical significance of the estimated coefficients matter when interpreting the regression results below. In other words, relative magnitudes of the coefficients are uninformative.

While ENDS Carbon produced CMP scores for 582 unique corporations, we used data for 433 of these in our analysis as we required corporations to have reported in both 2009 and 2010 and not all did. We restricted our sample in this way to avoid what we call the time-order problem. That is, if we were using the whole dataset covering 2007 20I0, the independent variable observations of interest (the CMPs) which were only measured once, in 20I0, would come after most of the dependent variable observations (measured in 20072010 ) in time. This would introduce ambiguity in the interpretation of the coefficients and make it impossible to draw any inference on the direction of causality between dependent and independent variables.

Although our dataset is novel and rich in several ways, allowing us to investigate the question above, it is important to note that it does not constitute a random sample. Most large, publically traded corporations are invited by CDP to respond to the CDP survey but those that respond do so voluntarily. Prior research on the characteristics of corporations that disclose their GHG emissions voluntarily has found that a corporation is more likely to disclose if it is in a relatively clean sector, if it has superior environmental performance relative to its peers, and if the proportion of reporting corporations in its sector is high (Brouhle \& Ramirez-Harrington, 2009; Matsumura

${ }^{3}$ For reasons discussed below, we are only able to use a subset of this dataset in our analysis.

${ }^{4} \mathrm{~A}$ detailed scoring scheme for each CMP similar to that reported in Table 2 is available on request. 


\section{Label (Tag)}

Policy \& commitments (Por)

Direct emissions targets:

scope and structure ( $\mathrm{PO} 2)$

Indirect emissions target ( $\left.\mathrm{PO}_{3}\right)$

Target strength (Po4)

Target horizon (Po5)

$\begin{array}{ll}\text { MEASUREMENT } & \begin{array}{c}\text { Scope } 1 \text { and } 2 \text { emissions } \\ \text { measurement (Mo1) }\end{array} \\ \text { Scope } 3 \text { emissions measurement (Mo2) } & \text { Boundary policy quality (Mo3) }\end{array}$

GHG accounting methods (Mo4)

Activity intensity (Mo5)

History [reporting] (Mo6)

DECISION MARKING Risk awareness - depth (DMo1)

Opportunity awareness (DMo2)

Responsibilities (DMo3)

Incentive structures (DMo4)

Emissions in corporate strategy (DMO5)

Carbon investment drivers (DMo6)

DISCLOUSRE

Fundamental disclosures (Dor)

Disclosures: information

availability (Do2)

Segmental disclosures (Do3)

\section{Description}

Extent to which corporation identifies emissions and climate change explicitly as issues to be managed through commitments and targets.

Quality of the corporation's emissions targets and the share of its scope 1 and 2 emissions the target addresses.

Presence and quality of the corporation's scope 3 emissions target.

Ambitiousness of the corporation's scope 1 and 2 emissions target relative to its global sector peers.

Length of the time horizon over which the emissions target is to be achieved.

Accuracy of the emissions measurement system implemented by the corporation for scope 1 and 2 emissions.

Number of relevant Scope 3 emissions sources reported.

Consistency and continuity of the boundary within which emissions are measured (e.g. equity share, financial/ operational control approaches, etc.)

Degree of recognition of emissions accounting standard used by the corporation, and the consistency of implementation of the standards over time.

Number of activity intensity metrics (e.g. emissions per unit of output) the corporation uses to measure emissions performance.

Number of years in which the corporation reported emissions.

Number of relevant risks recognized and assessed by the corporation and whether the corporation identifies key sector-specific risks.

Number of relevant opportunities recognized by the corporation and whether the corporation identifies key sector-specific opportunities.

Level at which the emissions management responsibility lies in corporation's management hierarchy and the length of time it has been there

Extent to which the corporation uses staff incentives for meeting emissions related goals.

Extent to which the corporation has integrated emissions management into its strategic planning, risk management and business strategy activities.

Number and quality of abatement measures identified by the corporation

Completeness of the corporation's disclosure regarding its emissions management activities

Variety of media through which the corporation publically releases at least two years of emissions data

Resolution at which the corporation releases emissions data into public domain (e.g. line of business, business unit/division) 


\begin{tabular}{cc}
\hline Label (Tag) & Description \\
\hline Assurance breadth (Do4) & $\begin{array}{c}\text { Whether one or more of scope 1, 2, or } 3 \text { emissions are } \\
\text { independently and externally verified. (e.g. scope } 1 \text { and } 2 \\
\text { are verified but not scope } 3 \text { ) }\end{array}$ \\
Assurance depth (Do5) & $\begin{array}{c}\text { Share of corporation's emissions which are independently and } \\
\text { externally verified. (e.g. 75\% of reported scope } 1 \text { and } 2 \\
\text { emissions are verified) }\end{array}$ \\
Assurance quality (Do6) & $\begin{array}{c}\text { Reputability of the assurance process used. } \\
\end{array}$
\end{tabular}

Table 1. Carbon management practices (CMPs) studied

Notes:

1) The descriptions above summarize the methodological details provided by ENDS Carbon. Additional information is available upon request.

2) The criteria used in assigning the top score for each CMP is provided in Table $A_{1}$ in the Appendix.

\begin{tabular}{ll} 
Points & \multicolumn{2}{c}{ Criterion } \\
\hline 0 & Evidence of direct emissions targets cannot be established \\
0 & No identifiable targets set \\
1 & Targets set cannot be converted to Annual Equivalent Targets (AETs) and may cover both direct and indirect emissions \\
2 & Well specified target(s) address some scope 1 or 2 emissions \\
3 & Well specified target(s) address $\geq 50 \%$ of aggregate global scope $1 \& 2$ emissions \\
4 & Well specified target(s) address $\geq 75 \%$ of aggregate global scope $1 \& 2$ emissions \\
5 & Well specified target(s) address $100 \%$ of aggregate global scope $1 \& 2$ emissions
\end{tabular}

Table 2. Scoring criteria for 'Po2: Direct emissions targets: scope and structure'

Notes:

1) The criteria used in assigning the top score for each CMP is provided in Table $A$ in the Appendix. Additional information is available on request.

et al., 20II). Nevertheless, the CDP is widely seen as the most comprehensive data source on corporate climate change practices and performance. We are not aware of any other large-N dataset containing information about carbon-specific management practices, meaning the CDP data, despite its challenges, is the best available. Our final dataset includes corporations from 39 sectors and I5 countries, and contains sufficient scale and variation for meaningful regression analysis.

\section{Model and estimation results}

To model the relationship of interest statistically, we fit the data described above to the following equation:

$$
\Delta \ln \left(\operatorname{co2}_{i} / \text { oprev }_{i}\right)=\alpha+M_{i} \boldsymbol{\beta}+S_{i} \zeta+C_{i} \boldsymbol{\theta}+\ln \left(e m p_{i}\right) \pi+\boldsymbol{\varepsilon}_{i}
$$

where $i$ indexes corporations. Our dependent variable measures the log change from 2009 to 2010 in GHG emissions normalized by the operating revenues of corporation $i$. More specifically the dependent variable is calculated as, 


\begin{tabular}{|c|c|c|c|c|c|c|}
\hline Variable & Obs & Mean & Std. Dev. & Min & Max & Source \\
\hline $\ln (\mathrm{co} 2)$ & 1627 & 12.587 & 2.541 & 4.111 & 18.999 & CDP \\
\hline $\ln (\mathrm{co} 2 /$ oprev) & 1603 & 8.490 & 2.096 & 1.417 & 19.595 & \\
\hline$\Delta \ln (\mathrm{co} 2 / o p r e v)$ & 1022 & -0.039 & 0.536 & -7.002 & 2.282 & \\
\hline $\ln (\mathrm{emp})$ & 1408 & 5.170 & 1.611 & -0.892 & 8.726 & ORBIS \\
\hline Po2: Direct emissions targets & 1627 & 2.459 & 2.299 & o & 5 & ENDS \\
\hline Po3: Indirect emissions target & 1627 & 1.227 & 2.042 & O & 5 & ENDS \\
\hline Po4: Target strength & 1627 & 1.763 & 2.048 & o & 5 & ENDS \\
\hline Po5: Target horizon & 1627 & 2.357 & 2.207 & O & 5 & ENDS \\
\hline Mol: Scope $1 \& 2$ & 1627 & 2.786 & 1.676 & 0 & 5 & ENDS \\
\hline Mo5: Activity intensity & 1627 & 4.184 & 1.749 & o & 5 & ENDS \\
\hline Mo6: History & 1627 & 3.398 & 1.981 & O & 5 & ENDS \\
\hline DMoı: Risk awareness - depth & 1627 & 2.649 & 2.018 & o & 5 & ENDS \\
\hline DMo2: Opportunity awareness & 1627 & 2.966 & 2.082 & o & 5 & ENDS \\
\hline DMo3: Responsibilities & 1627 & 3.412 & 1.821 & o & 5 & ENDS \\
\hline DMo4: Incentive structures & 1627 & 1.121 & 1.333 & O & 5 & ENDS \\
\hline DMo5: Emissions in corporate strategy & 1627 & 3.800 & 1.759 & o & 5 & ENDS \\
\hline DMo6: Carbon investment drivers & 1627 & 3.844 & 1.902 & O & 5 & ENDS \\
\hline Dor: Fundamental disclosures & 1627 & 4.001 & 1.437 & O & 5 & ENDS \\
\hline
\end{tabular}

Table 3. Summary statistics

Notes:

1) $\ln (\mathrm{CO} 2)$ is the natural log of the sum of scope 1 and 2 emissions measured in tons of $\mathrm{CO}_{2} \mathrm{e}$.

2) In (oprev) is the natural log of operating revenue measured in millions of nominal US\$.

3) $\Delta \ln$ (CO2/oprev) is the change in $\ln$ (cO2/oprev) between 2009 and 2010.

For details regarding individual carbon management practices see Tables 1.

$$
\Delta \ln \left(\operatorname{co2}_{i} / \text { oprev }_{i}\right)=\ln \left(\operatorname{co2}_{i} / \text { oprev }_{i}\right)_{2010}-\ln \left(\operatorname{co2}_{i} / \text { oprev }_{i}\right)_{2009}
$$

The dependent variable accounts for the heterogeneity of individual corporations not captured elsewhere because it is expressed in log changes.

On the right hand side of Eqn (I), matrix $M_{i}$ contains the data on CMP scores. $M_{i}$ is time-invariant since we only observe it in the ENDS Carbon data for one year, 20I0. $S_{i}$ contains the dummy variables for secondary and tertiary sectors. $C_{i}$ contains the dummy variables for European Union, Japan, and Australia, which are equal to one if the corporation is European, Japanese, and Australian, respectively. ${ }^{5}$ Since change in emissions might be sensitive to corporation size even after normalization, the log of employment is included to account for the scale of the corporation. The term $\alpha$ is an intercept and $\varepsilon$ is an i.i.d. error term. Table 3 gives descriptive statistics for all variables.

${ }^{5}$ The reference group consists of corporations from non-EU European countries, i.e., Norway and Switzerland. 
We estimate (I) using simple ordinary least squares. The coefficients of interest are in the vector $\boldsymbol{\beta}$. The results are reported in Table 4 .

We focused on the key patterns that emerged from our analysis. When we analyzed the entire dataset of 433 corporations (column I), we found no statistically significant evidence that any of the 23 carbon management practices had influenced corporate GHG emissions. To test whether this was as a result of limitations in the quality of the data on corporate GHG emissions, in column 2 we repeated the analysis but restricted the sample to those corporations that were assessed by ENDS Carbon to have better than average quality of GHG emissions measurement. ${ }^{6}$ Again we found no statistically significant evidence that the take-up and implementation of any of the I7 management practices has impacted on GHG emissions.

We then excluded the financial sector from the sample (column 3), on the basis that corporations within this sector are likely to have lower levels of direct emissions. This additional restriction can account for some of the self-selection effects that make the sample non-random. As discussed above, prior research has found that corporations that are in relatively clean sectors are more likely to voluntarily disclose their emissions. Figure I illustrates the distribution of corporations in our dataset across sectors.

For this sub-sample, which only includes non-financial sector corporations with better-than-average quality of GHG measurement, we found some evidence of an impact of CMPs on emissions performance. Column 3 shows lower levels of emissions growth for corporations with stronger policies and commitments in place to address climate change, for corporations with explicit emissions reduction targets, and for corporations that created financial incentives for emissions reduction. However, we did not find an observable impact for any of the I4 other CMPs.

This suggests little discernible impact on emissions performance for all the other CMPs that we consider. They include the extent to which responsibilities for carbon management have been assigned to a member of the board, the quality and quantity of GHG-related information disclosure, and the quality of assurance of reported GHGs. This finding is clearly at odds with the expectation in the literature that the presence and implementation of CMPs should improve corporate GHG performance.

In columns 4 and 5 we restrict the sample further to include only the 'dirty' corporations or only the corporations that are in the sectors that are regulated under the European Emissions Trading Scheme (ETS). ${ }^{7}$ This greatly reduces the size of the estimation sample but produces similar results. Moreover, those few CMPs which are significant in each of columns 3 to 5 are not consistently so across columns, with the exception of target strength which is negative and significant in columns 4 and 5. Taken together these observations align well with our main conclusion that it is not possible to identify a statistically significant association between most CMPs and emissions performance.

It is important to mention that we tested and eventually rejected for methodological reasons a wide range of estimation approaches in arriving at the preferred specifications in Table 4. We tried various dependent variable measures including absolute emission levels rather than emissions relative to output (the results were largely the same). We ran purely cross-sectional estimations exploring the simple direction, strength, and significance of association between emissions and the CMPs, as opposed to the estimations of the relationship presented here. We tried constructing a single index of the CMPs rather than including the CMPs individually. We tried grouping the CMPs into their different management practice categories and, separately, including just the CMPs that might be expected to reduce emissions directly and omitting those that might contribute to emissions reductions indirectly. We explored binary and continuous measures of the individual CMPs themselves. We feel that the extensive tests we subjected the data to in arriving at the preferred estimation strategy described above, and reflected in the specifications and results in Table 4 , have ensured the best practicable methodological treatment of the data given their inherent challenges.

\section{Discussion of Results}

We propose three possible explanations for these results, all of which have significant implications for policy and practice. The first is that whilst the most comprehensive and authoritative available data on corporations and

\footnotetext{
${ }^{6}$ Specifically, the sample includes only those corporations whose aggregate measurement score is greater than or equal to the median of the aggregate score across all corporations. We denote these as corporations with a 'high quality of measurement'.

${ }^{7}$ Table A2 in the appendix shows which corporations were considered to be subject to the ETS, on the basis of their industry sector.
} 


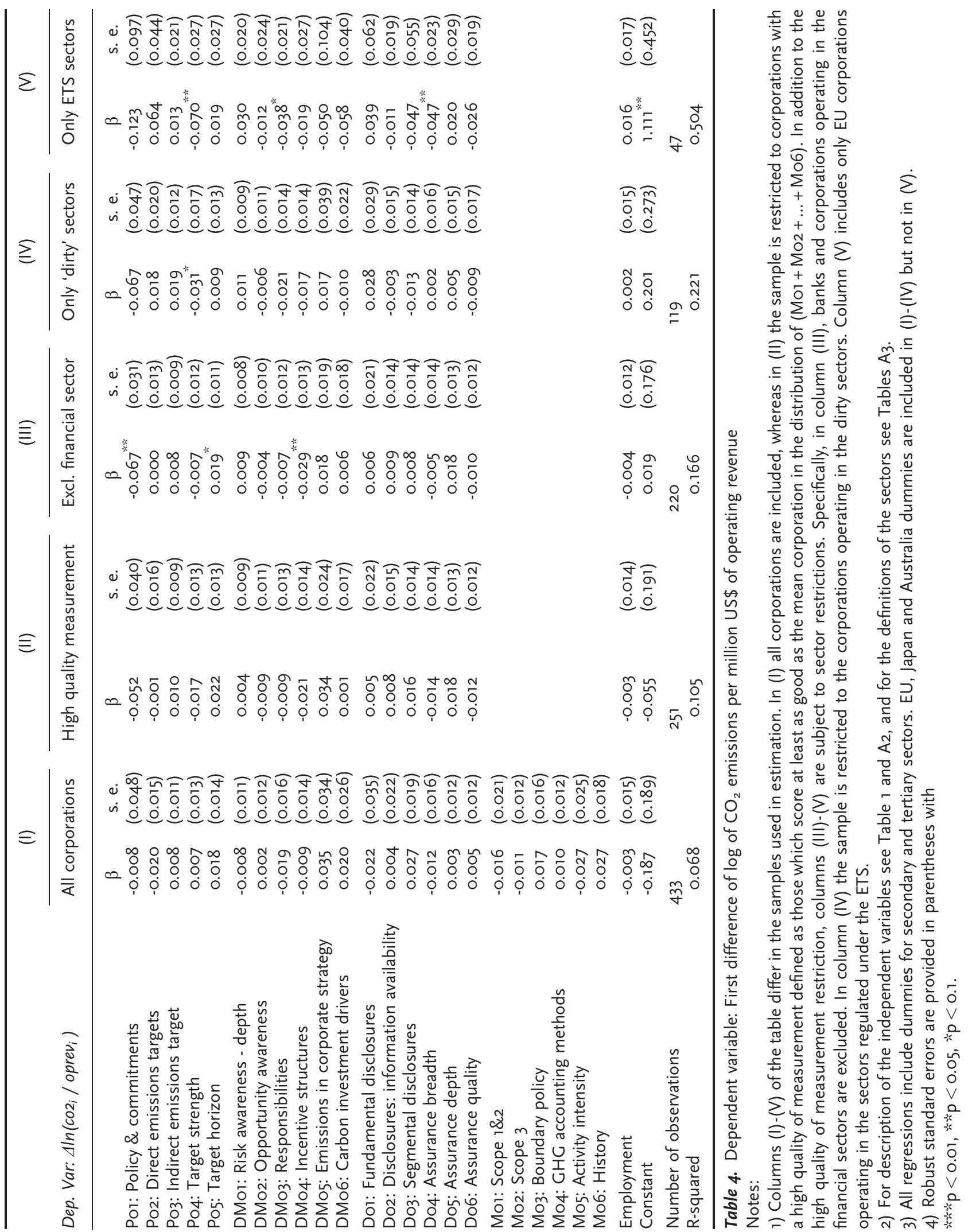




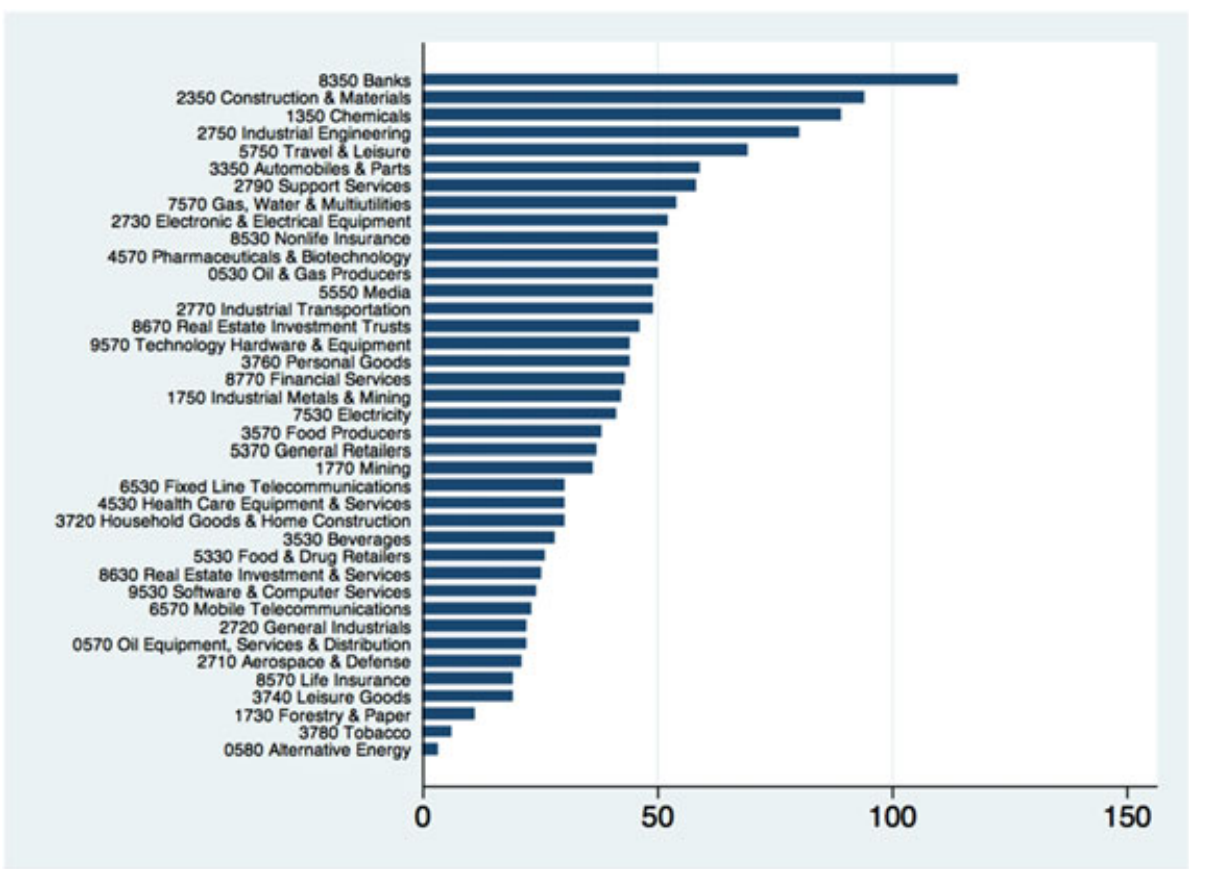

Note: the corporations in the dataset represent 39 economic sectors. Consistent with prior research that has found that corporations are more likely to disclose their emissions if they reside in a relatively clean sector $[20,21]$, the sector with the largest number of reporting corporations in our data is Banks.

Figure 1. Distribution of corporations by industry sectors

GHG emissions tells us a lot about the implementation of corporate CMPs, it does not reveal the true impact of these practices on GHG emissions. This could be because of self-selection issues in the corporations that choose to report to CDP or because the data that the corporations supply is incomplete or inconsistent. These reasons could indicate that more standardized forms of corporate emissions accounting, monitoring and disclosure are needed. This in turn feeds into the debate on the limitations of voluntary reporting of corporate environmental performance and on the potential benefits of standardized, mandatory reporting (Kolk et al., 2008; Sullivan \& Gouldson, 20I2).

The central argument for the introduction of standardized mandatory reporting is as follows. The more complete and consistent are the data about corporate carbon management and GHG emissions, the easier it will be for stakeholders (including those within the corporations themselves) to monitor progress, to compare performance, and to exert influence. However, even if a mandatory reporting requirement were introduced, it is likely that this would only be a partial solution. Evidence from other mandatory schemes suggests that corporations could retain significant flexibility in the ways they measure and report their emissions (Gouldson \& Sullivan, 2007). Furthermore, in the absence of a global agreement on corporate carbon reporting, differences between national schemes will make it difficult to compare the data produced from different jurisdictions (Sullivan \& Gouldson, 2007). Our experience with what is to our knowledge the most comprehensive quantitative data on corporate emission and CMPs suggests mandatory reporting procedures based on fully random sampling of corporations could go a long way to helping corporate managers understand which CMPs are most effective.

The second possible explanation is that the implementation of these CMPs may not lead to immediately observable reductions in GHG emissions. Whilst many analysts highlight the availability of some 'early wins' (through the adoption of measures with very short payback periods, often referred to as 'low-hanging fruit') in energy and carbon management (DeSimone \& Popoff, 2000; Shipley \& Elliot, 2006), it may be that corporations have already exploited these measures by the time they implement the CMPs they describe in their reporting to CDP. The consequence is that it may take time for the impacts of CMPs to become observable. There has been some 
evidence of this delayed impact elsewhere (Wu \& Teng, 20I4). Even so, in a context where many analysts have highlighted the need for rapid reductions in emissions to avoid dangerous climate change, the extent of this delay becomes critically important.

The third possible explanation is that the CMPs that are being implemented by a large proportion of the world's largest corporations are not sufficiently impact-oriented. Corporations might be assuming that the mere presence of different CMPs is reducing their GHG emissions without assessing the extent to which the CMPs are actually doing so. Expressed more directly, it could be that more attention should be paid not to the presence but to the impact of corporate CMPs on the emissions that they are supposed to be reducing.

While these are all - individually or collectively - important conclusions, they should be qualified by noting that we have only been able to analyze a relatively small proportion of all corporations that report emission to CDP. While we have tested a wide range of estimation methods, we have only been able to study a limited time period with the available data. That is, our results describe a short-run relationship between CMPs and GHG emissions performance. More extensive future analysis may point to a more broadly recognizable relationship. Research priorities in this area are therefore to consider a larger, random sample of corporations over longer time periods.

Due in part to the non-random nature of our sample, these results should not be interpreted as applying to individual corporations or to the universe of corporations from which the CDP data is drawn. There may well be corporations that have delivered significant GHG reductions as a result of adopting the sort of CMPs discussed here.

Finally, we note that there may be an element of reverse causality in our analysis. In that context, we would need to consider whether it is the level, or the rate of change, of GHG emissions that drives the implementation of a CMP (rather than, as we considered, whether the CMP drives GHG emissions). For instance, a positive coefficient on a management practice variable may suggest that corporations with a high emissions intensity growth rate are more likely to implement that practice because reducing energy costs is a stronger imperative for dirty corporations than for clean ones. Or it might be the case that corporations with a high growth rate are subject to a specific policy requiring the adoption of new forms of environmental management.

\section{Conclusions and Implications}

It is something of an article of faith among policymakers, investors, and companies that good corporate management practices will inevitably lead to better performance (in terms of GHG emissions) outcomes. This assumption has underpinned many of the public policy measures and corporate management initiatives directed at reducing corporate GHG emissions. The fact that, even using the most comprehensive and authoritative data on carbon-specific CMPs and applying the best practicable estimation methods available, we have found limited evidence of an impact of CMPs on corporate carbon emissions is therefore of profound importance, to policymakers, to companies and to society as a whole.

However, our analysis does not tell us is whether this finding is because of limitations in the data that are available, because of the absence of a causal relationship between CMPs and performance, or because companies do not place sufficient emphasis on performance or outcomes in their carbon management initiatives. This paper therefore points to three important recommendations for companies.

The first is that companies need to strengthen the quality and comparability of their reporting to the CDP. This requires that they align their reporting with the World Business Council's Greenhouse Gas Reporting Protocol (WBCSD, 2004; 20II), that they clearly define the scope and boundaries of their reporting, that they have a consistent approach to calculating and reporting their emissions, that they clearly document the assumptions, protocols and emissions factors they use in their reporting, and that they have their data independently assured (e.g. the proposals in Sullivan \& Gouldson, 20I2).

The second is that companies need to explicitly discuss how the adoption of corporate management practices influences corporate greenhouse gas emissions. At present, the CDP encourages companies to explain the contribution that specific actions (e.g. the adoption of particular energy saving technologies, the changing of fuel or electricity sources) makes to their greenhouse gas emissions. Generally, this is presented in terms of the quantity of greenhouse gas emissions avoided or abated. While helpful, this is not sufficient to answer the questions raised 
by this paper. Ideally companies should explain how the carbon management practices they have adopted have influenced the carbon management actions that they have taken. In turn, they should explain how these actions have both contributed to GHG emissions avoided or abated (as they do at present) and how these actions, together, have influenced the company's total GHG emissions. The CDP is moving in this direction as it encourages companies to provide some high level explanation of overall changes in their greenhouse gas emissions. However, to date, this relationship between carbon management practices, actions, and performance is not clearly drawn for the vast majority of companies.

The third is that companies need to shift their focus from relative to absolute performance. That is, they should express their targets in terms of the absolute GHG emission reductions they are looking to achieve, and they should ensure that their management practices and processes are directed towards this end (i.e., of reducing absolute emissions rather than seeking to improve energy efficiency or energy intensity). We recognize that this is a demanding recommendation although we note that there is evidence that companies can deliver consistent yearon-year reductions in their greenhouse gas emissions over a decade or more (Sullivan \& Gouldson, 20I3), and that leading companies are prepared to commit to absolute emission reduction targets that extend over multiple decades (Gouldson \& Sullivan, 20I3).

\section{Acknowledgement}

We are grateful to ENDS Carbon for providing us with the data and responding to our queries. There is no commercial or other relationship between ENDS Carbon and any of the authors of this paper. The authors would like to acknowledge the financial support of the ESRC Centre for Climate Change Economics and Policy and Munich Re, and also from the Grantham Foundation for the Protection of the Environment. The usual disclaimer applies.

\section{References}

Bloom N, Genakos C, Martin R, Sadun R. 2oio. Modern management: Good for the environment or just hot air? The Economic Journal I20: $55 \mathrm{I}-572$.

Bloom N, Van Reenan J. 2010. New approaches to surveying organizations. American Economic Review Papers and Proceedings Ioo: I05-I09.

Boiral O, Henri J-F, Talbot D. 20I2. Modelling the impacts of corporate commitment on climate change. Business Strategy and the Environment 2I: $495-516$.

Brouhle K, Ramirez-Harrington D. 2009. Firm strategy and the Canadian voluntary climate challenge and registry (VCR). Business Strategy and the Environment 18: 360-379.

CDP. 2006. Carbon Disclosure Project Report 2006: Global FT500. Carbon Disclosure Project: London.

CDP. 20I0. Carbon Disclosure Project 20I0: Global 500 Report. Carbon Disclosure Project: London.

CDP. 20I2. Business Resilience in an Uncertain, Resource Constrained World: CDP Global 500 Climate Change Report. Carbon Disclosure Project: London.

Dahlström K, Howes C, Leinster P, Skea J. 2003. Environmental management systems and company performance: Assessing the case for extending risk-based regulation. European Environment 13: I87-203.

DeSimone L, Popoff F. 2000. Eco-efficiency: The business link to sustainable development. MIT Press: Cambridge.

Gouldson A, Sullivan R. 2007. Corporate environmentalism: Tracing the links between policies and performance using corporate reports and public registers. Business Strategy and Environment I6(I): I-II.

Gouldson A, Sullivan R. 20I3. Long-term corporate climate change targets: What could they deliver? Environmental Science Q Policy 27: I-IO.

Greer J, Bruno K. I996. Greenwash: The Reality Behind Corporate Environmentalism. Third World Network: Penang, and Apex Press: New York.

Hoffman A. 2006. Getting Ahead of the Curve: Corporate strategies that address climate change. Pew Charitable Trusts: Philadelphia.

Kolk A, Levy D, Pinkse J. 2008. Corporate responses in an emerging climate regime: The institutionalization and commensuration of carbon disclosure. European Accounting Review I7: 719-745.

Konnola T, Unruh G. 2007. Really changing the course: The limitations of environmental management systems for innovation. Business Strategy and the Environment I6: 525-537.

Lee S-Y. 20I2. Corporate carbon strategies in responding to climate change. Business Strategy and the Environment 2I: 33-48.

Matsumura E, Prakash R, Vera-Muñoz S. 20II. Voluntary disclosures and firm-value effects of carbon emissions. Working Paper, 6 April 201 . Wisconsin School of Business, University of Maddison, Wisconsin. 
Pinkse J, Kolk A. 2009. International Business and Global Climate Change. Routledge: Abingdon.

Ramus C, Montiel I. 2005. When are corporate environmental policies a form of greenwashing? Business and Society 44: 377-4I4.

Shipley A, Elliot R. 2006. Ripe for the Picking: Have we exhausted the low hanging fruit in the industrial sector? American Council for an Energy Efficient Economy, Report No. IEo6I. https://www.greenbiz.com/sites/default/files/document/CustomOı6C45F69267.pdf [I5 November 2013.]

Sullivan R, Gouldson A. 2007. Pollutant release and transfer registers: Examining the value of government-led reporting on corporate environmental performance. Corporate Social Responsibility and Environmental Management 14: 263-273.

Sullivan R, Gouldson A. 20I2. Does voluntary carbon reporting meet investors' needs? Journal of Cleaner Production 36: 60-67.

Sullivan R, Gouldson A. 2013. Ten years of corporate action on climate change: What do we have to show for it? Energy Policy 60: 733-740.

Theyel G. 2000. Management practices for environmental innovation and performance. International Journal of Operations \& Production Management 20(2): 249-266.

Weinhofer G, Busch T. 20I3. Corporate strategies for managing climate risks. Business Strategy and the Environment 22: I2I-I44.

WBCSD. 2004. The Greenhouse Gas Protocol: A Corporate Accounting and Reporting Standard. Revised Edition. World Business Council for Sustainable Development and World Resources Institute: Geneva.

WBCSD, WRI. 20II. Corporate Value Chain (Scope 3) Accounting and Reporting Standard. WBCSD: Geneva.

Wu M-J, Teng S-Y. 20I4. Environmental commitment and economic performance: Short-term pain for long-term gain. Environmental Policy and Governance 24: 16-27. 


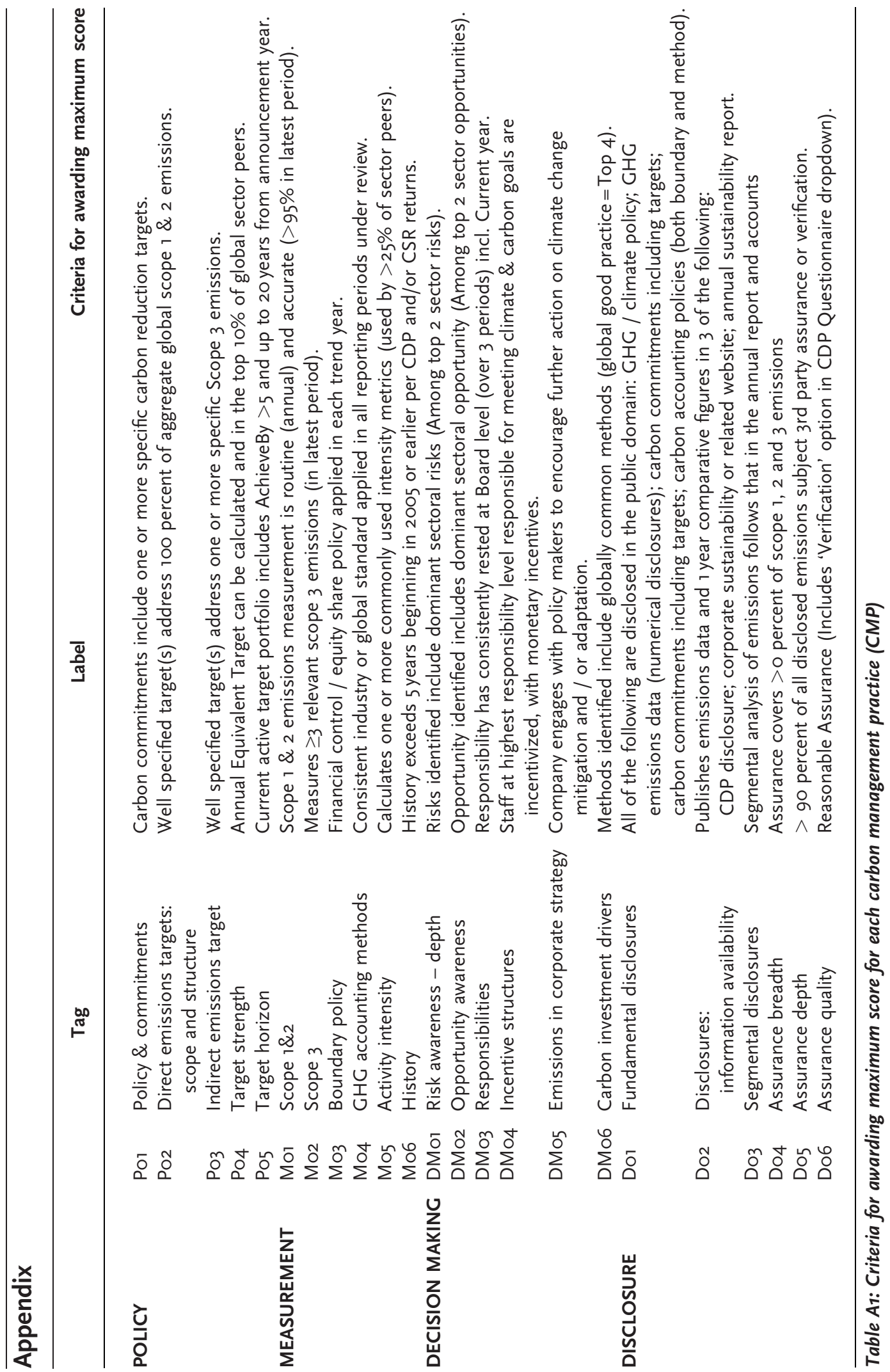




\begin{tabular}{|c|c|c|c|c|c|}
\hline & Dirty & ETS & Primary & Secondary & Tertiary \\
\hline Aerospace \& Defence & $*$ & & & $*$ & \\
\hline Alternative Energy & & & & $*$ & \\
\hline Automobiles \& Parts & $*$ & & & $*$ & \\
\hline Banks & & & & & $*$ \\
\hline Beverages & $*$ & & & $*$ & \\
\hline Chemicals & $*$ & $*$ & & $*$ & \\
\hline Construction \& Materials & $*$ & & & $*$ & \\
\hline Electricity & $*$ & $*$ & $*$ & & \\
\hline Electronic \& Electrical Equipment & $*$ & & & $*$ & \\
\hline Financial Services & & & & & $*$ \\
\hline Fixed Line Telecommunications & & & & & $*$ \\
\hline Food \& Drug Retailers & & & & & $*$ \\
\hline Food Producers & $*$ & & & $*$ & \\
\hline Forestry \& Paper & $*$ & $*$ & $*$ & & \\
\hline Gas, Water \& Multiutilities & $*$ & $*$ & $*$ & & \\
\hline General Industrials & $*$ & & & $*$ & \\
\hline General Retailers & & & & & $*$ \\
\hline Health Care Equipment \& Services & & & & & $*$ \\
\hline Household Goods \& Home Construction & $*$ & & & & $*$ \\
\hline Industrial Engineering & & & & & $*$ \\
\hline Industrial Metals \& Mining & $*$ & $*$ & $*$ & & \\
\hline Industrial Transportation & $*$ & & & $*$ & \\
\hline Leisure Goods & $*$ & & & $*$ & \\
\hline Life Insurance & & & & & $*$ \\
\hline Media & & & & & $*$ \\
\hline Mining & $*$ & $*$ & $*$ & & \\
\hline Mobile Telecommunications & & & & & $*$ \\
\hline Nonlife Insurance & & & & & $*$ \\
\hline Oil \& Gas Producers & $*$ & $*$ & $*$ & & \\
\hline Oil Equipment, Services \& Distribution & $*$ & & $*$ & & \\
\hline Personal Goods & & & & & $*$ \\
\hline Pharmaceuticals \& Biotechnology & & & & & $*$ \\
\hline Real Estate Investment \& Services & & & & & $*$ \\
\hline Software \& Computer Services & & & & & $*$ \\
\hline Support Services & & & & & $*$ \\
\hline Technology Hardware \& Equipment & $*$ & & & $*$ & \\
\hline Tobacco & $*$ & & & $*$ & \\
\hline Travel \& Leisure & $*$ & & & & $*$ \\
\hline
\end{tabular}

Table A2: Relevant classifications 